\title{
On the Habitability of Desert Varnish: a Combined Study by Micro-Raman Spectroscopy, X-Ray Diffraction and Methylated Pyrolysis-Gas Chromatography-Mass Spectrometry
}

C. Malherbe ${ }^{1,2}$, I. B. Hutchinson ${ }^{1}$, R. Ingley ${ }^{1}$, A. Boom ${ }^{3}$, A. S. Carr ${ }^{3}$, H. Edwards ${ }^{1}$, B. Vertruyen ${ }^{4}$, B. Gilbert $^{2}$, G. Eppe ${ }^{2}$

\author{
${ }^{1}$ Department of Physics and Astronomy, University of Leicester, LE1 7RH, UK \\ ${ }^{2}$ Laboratory of Inorganic Analytical Chemistry, Department of Chemistry, University of Liège, 4000 \\ Liège 1 , Belgium \\ ${ }^{3}$ Department of Geography, University of Leicester, LE1 7RH, UK \\ ${ }^{4}$ LCIS/GREENMAT, Department of Chemistry, University of Liège, 4000 Liège, Belgium
}

\section{Corresponding author}

Malherbe Cedric

c.malherbe@ulg.ac.be / cm618@leicester.ac.uk

\section{Running title}

Habitability of Desert Varnish

\begin{abstract}
In 2020, the ESA ExoMars and NASA Mars 2020 missions will be launched to Mars, searching for evidence of past and present life. In preparation for these missions, terrestrial analogue samples of rock formations on Mars are studied in detail in order to optimize the scientific information that the analytical instrumentation will return. Desert varnishes are thin mineral coatings found on rocks in arid and semi-arid environments on Earth that are recognized as analogue samples. During the formation of desert varnishes (which takes many hundreds of years) organic matter is incorporated and microorganisms may also play an active role in the formation process. During this study, four complementary analytical techniques proposed for
\end{abstract}


Mars missions (X-ray diffraction, Raman spectroscopy, elemental analysis and pyrolysis-gas chromatography-mass spectrometry) were used to interrogate samples of desert varnish and to describe their capacity to sustain life under extreme scenario. For the first time, both the geochemistry and the organic compounds associated with desert varnish are described using an identical set of samples. XRD and Raman spectroscopy measurements were used to nondestructively interrogate the mineralogy of the samples. In addition, the use of Raman spectroscopy instruments enabled the detection of $\beta$-carotene, a highly Raman-active biomarker. The content and the nature of the organic material in the samples was further investigated using elemental analysis and methylated Py-GC-MS and a bacterial origin was determined to be likely. In the context of planetary exploration, we describe the habitable nature of desert varnish based on the bio-geochemical composition of the samples. Possible interference of the geological substrate on the detectability of pyrolysis products is also suggested.

Keywords: Desert varnish, habitability, Raman spectroscopy, Py-CG-MS, XRD, ExoMars, planetary science

\section{Introduction}

In 2018, the ExoMars Rover mission (ESA/Roscosmos) will be launched to explore the surface of Mars (ExoMars mission, 2015). The scientific objectives of the Pasteur payload on board the ExoMars rover include: (a) geochemical analyses of soils and rocks at both the surface and in the subsurface, (b) identification of geological formations which may preserve potential traces of life and (c) the search for evidence of extant or extinct life (Rull et al., 2011). At the center of these science goals lies the question of the habitability of Mars; i.e. was Mars ever able to support life, and could life now survive despite the harsh conditions? That question was 
also a key aspect of the science goals of the NASA's MSL Curiosity rover, and is a key objective of the NASA Mars 2020 mission (planned for launch in 2020) (NASA Mars 2020, 2014). In preparation for these missions, developing an understandings of: the appearance and evolution of life on Earth (the only location in the Universe where life as we comprehend it was confirmed), as well as the preservation of evidence of life, are of utmost importance. To this end terrestrial samples recovered from extreme environments on Earth, that replicate one or more aspect of the environmental conditions on Mars (dryness, coldness, poor nutriment supply, high UV insolation, etc), are currently being interrogated using a wide range of analytical techniques proposed for rover missions (Hutchinson et al., 2014; Vitek et al., 2014; Fairén et al., 2010; Edwards et al., 2013; Jorge Villar and Edwards, 2006). In particular, some of these analogue samples comprise microorganisms that survive on or in rocks.

Amongst the variety of samples identified as potential Martian analogues, specimens of desert varnish represent ideal candidates to document the habitable character of biogeological samples. Indeed, desert varnish samples primarily comprise clays, iron (III) and manganese (IV) oxides (Potter and Rossman, 1979), three minerals that are understood to potentially support life on Earth (Grotzinger et al., 2014). Desert varnish are only several microns in thickness and can be found on the outer part of rocks in dry, stable, cold or hot environments on Earth (Dorn, 2008). Although the suggested microbial origin of desert varnish is still controversial (Perry et al., 2006; Dorn, 2007), desert varnishes are associated with extremophile biological colonization (Perry et al., 2003; Schelble et al., 2005; Dorn, 2008). Hard desert varnish skins may also preserve organic matter in hostile environments for considerable periods of time (Mancinelli and White, 1996; DiGregorio, 2002). Furthermore, manganese-rich coatings (similar to terrestrial desert varnish) have been identified on Martian rocks by the ChemCam instrument on the Curiosity rover (Lanza et al., 2014). 
For planetary exploration, assessing the habitability of a geological sample involves verifying the presence of the minimum set of components necessary for life. For example, astrobiologists, who investigate the evolution and the limits of known life, have identified the following requirements for life (Rothery et al., 2011):

(a) Liquid water should be available, since water is the universal solvent which allows the chemical reactions necessary to sustain life. The presence of solid water, frozen at the poles of Mars, has been confirmed and seasonal flows of gaseous water are suggested (Mellon et al., 2009). Recently, NASA confirms that liquid water could still flow on the surface of Mars today (Ojha et al., 2015; NASA Water on Mars, 2015). However, although liquid water could be present on Mars, the surface of Mars remains quite dry. On Earth, some microorganisms are known to survive dry periods using the water trapped in hydrous minerals (which are capable of storing water) such as gypsum, feldspar, hematite or clays (Sadooni et al., 2010). Seasonal flows of liquid and gaseous water on Mars could possibly maintain a sufficient degree of rock hydration and sustain microorganism activities. The hydration state of the minerals within a rock substrate is therefore an important measure of its habitability.

(b) Life also requires a source of energy to power microorganism metabolisms (Grotzinger et al., 2014). On Earth, most of the energy supplied to living organisms comes from the sun (via photosynthesis), although many autotroph microorganisms have also been found which are capable of drawing energy from redox reactions in their immediate environment (chemosynthesis) (Fisk and Giovannoni, 1999; Ehrlich and Newman, 2009). In that respect, the presence of iron or manganese rich minerals is of interest as the redox couple $\mathrm{Fe}^{3+} / \mathrm{Fe}^{2+}$ has been reported to drive the metabolism processes of microbes on Earth (Roden and Zachara, 1996). Equally, a mineral source of the manganese is relevant to the habitability of a rock, since some terrestrial microorganisms are also known to draw energy from the redox reactions of manganese (Marnocha and Dixon, 2013). 
(c) Finally, life needs nutriments such as sources of carbon, hydrogen, nitrogen, oxygen, phosphorus, sulfur and iron (Rothery et al., 2011). These atoms are sourced from the environment and constitute the building blocks of life as we know it. Lipids, carbohydrates, amino acids and nucleic acids are the building blocks of the living cells and are mainly carbonbased molecules (Schulze-Makuch and Irwin, 2008). Some of these building blocks, which are nothing more than small organic molecules can, however, also be produced abiotically (Johnson et al. 2008; Chyba and Sagan, 1992). Indeed, there are lots of organic molecules in space (Ehrenfreund and Charnley, 2000), but evidence of alien life is still to be discovered. Extraterrestrial organic molecules as well as carbon deposits can potentially be used as nutrients for forms of life and therefore, are an indicator of habitability. These building blocks are actually quite important in the context of searching for evidence of life (past or present). When combined, polymerized or generated by biological processes, organic molecules constitute molecular proofs of life and are then known as biomarkers (Edwards, 2007). However, it must be stressed that the notion of biomarker, in the context of astrobiology, often includes not only the carbon remains of life (extinct or extant), but also indirect fingerprints of life such as textural patterns in geological records (preserving the structure of biological communities) or minerals whose deposition was affected by microorganisms (Konhauser and Riding, 2012).

In order to assess the habitability of Mars, the ExoMars and NASA 2020 rovers will interrogate the surface and subsurface of the planet searching for biomarkers which might be contained within a geological host. Many analytical techniques have been proposed to document the composition of the surface and subsurface of Mars, in terms of both geo- and biomarkers. These include: X-ray diffraction (XRD), Raman spectroscopy (RS) and pyrolysisgas chromatography-mass spectrometry (Py-GC-MS). 
$\mathrm{X}$-ray diffraction is a standard technique used to identify minerals and to characterize their respective atomic structure and is a powerful tool for identifying well crystalized materials (geomarkers). It suffers from a lack of sensitivity to amorphous phases and biomarkers (which are not naturally crystallized). XRD was initially proposed to be part of the ExoMars rover (MARS-XRD instrument) (Marinangeli et al., 2007), but was ultimately de-scoped (in 2012) following a reduction in the payload mass.

Raman spectroscopy is a non-destructive technique which requires no mechanical or chemical preparation of the samples and which is sensitive to both geo- and biomarkers (Jorge Villar et al., 2006; Miralles et al., 2012; Jehlička and Oren, 2013). During the ExoMars mission, a Raman instrument (the Raman Laser Spectrometer; RLS) will provide analytical interrogation of crushed rock specimens acquired from the surface and subsurface of Mars (Rull et al., 2011). Miniaturized Raman spectrometers have been developed and used for many different analytical applications including the analysis of Mars analogue samples (Vitek et al., 2014; Jehlička et al., 2010; Jehlička et al., 2011 Vandenabeele et al., 2014). In a previous publication (Malherbe et al., 2015), we reported a study of 7 desert varnish samples recovered from the Mojave Desert and using (for the first time) miniaturized Raman spectrometers operating in the green visible (i.e. $532 \mathrm{~nm}$, as is currently baselined for both ExoMars and the Mars 2020) and in the nearinfrared $(785 \mathrm{~nm})$. The miniaturized spectrometers were operated in acquisition modes representative of those to be adopted by the rover instruments. Successful characterization of the samples was achieved using miniaturized instruments for both the $532 \mathrm{~nm}$ and $785 \mathrm{~nm}$ excitation sources. The detection of $\beta$-carotene in some of the samples was reported using a 532 $\mathrm{nm}$ excitation laser. Spectral analysis complications caused by the presence of rare earth element photoluminescence when using a $785 \mathrm{~nm}$ excitation laser were also discussed.

Pyrolysis-gas chromatography-mass spectrometry (py-GC/MS), Elemental Analysis (EA) to determine total organic carbon analysis (TOC) and stable carbon isotope analysis 
$\left(\delta^{13} \mathrm{C}_{\mathrm{TOC}}\right)$ are standard methods used to interrogate the nature of the organic matter in soils and sediments (e.g. Saiz-Jimenez, 1986; Derenne and Quenea, 2016). Fragmentation of macromolecular organic matter via rapid heating in an inert atmosphere results in the product of GC-amenable pyrolysis products, from which the original macromolecular structures may be inferred. To assist the reliable identification of precursor structures, samples can also be pretreated with online methylating agent, tetramethyl ammonium hydroxide (TMAH). Py-GCMS has been proposed for a number of exploratory mission on Mars (see also GonzalezNavarro et al., 2003) and will be the principal operating mode of the Mars Organic Molecule Analyzer (MOMA instrument) on the ExoMars mission (Brinckerhoff et al., 2013). Several studies considering Mars analogue material have previously considered pyrolysis methods (e.g. Gonzalez-Navarro et al., 2003, 2009; Goffroy-Rodier et al., 2009) although none, to our knowledge have applied this method to desert varnish material and/or combined this method with Raman spectroscopy in Earth analogue studies.

In preparation for future missions to Mars, we present a study of powdered specimens of desert varnish recovered from the Mojave Desert using a suite of four analytical techniques: XRD, RS, TOC and Py-GC-MS. These are used to investigate the samples and to consider the complementarity of these four methods in characterizing the analogue samples using laboratory instruments. The results are reported in the context of describing the habitable nature of a biogeological sample using spectroscopic and spectrometric information. The data reported here will also support further optimization /characterization of prototype instruments.

\section{Materials and Methods}

\subsection{Samples}


Several specimens of rock exhibiting an apparently varnished surface were obtained from two separate locations in the Mojave Desert, USA. The samples were described in detail elsewhere (Malherbe at al., 2015). Three samples (DV1, DV2 and DV3) were retrieved from a stabilized alluvial fan surface from the Funeral Mountains east of Death Valley. They are covered with a black varnish. Four others samples (CV1, CV2, CV3 and CV4) were retrieved from a desert pavement surface overlying a stabilized aeolian deposit in the Cady Mountains, east of Barstow, California. They are coated with a brownish varnish.

Following the in-situ RLS analyses using portable instrumentation, reported in Malherbe et al. (2015), the desert varnish coatings were removed from the rock substrata using sterilized stainless steel tools. A flat spatula was used to remove the desert varnish from outer surfaces while a small hook was used to remove the desert varnish in small asperities. Images of the obtained desert varnish samples are presented in Figure 1. These were obtained using a Brunel SP60P microscope (through a x10 objective, $0.25 \mathrm{NA}$ ) equipped with a Canon EOS $1100 \mathrm{D}$ camera. Clearly, the averaged particle size was smaller for the samples originating from Death Valley (average of $100 \mu \mathrm{m}$ in diameter) than for the samples originating from the Cady Valley (ranging from 100 up to $600 \mu \mathrm{m}$ in diameter). These grain size values are in agreement with the grain size delivered by the ExoMars Sample Preparation and Delivery System (SPDS) (Schulte et al., 2010). For both sets of samples, the majority of the grains appeared to be orange to red or transparent. Silvery dark grains were observed for the samples DV1, DV2 and DV3, but not for the samples CV1, CV2, CV3 and CV4 (although for these samples, darker features are observed on some selected grains).

FIG. 1

\subsection{X-ray diffraction}

XRD diffractograms of all samples of desert varnish were recorded with a parallel beam diffractometer (Bruker D8, Cu Ka radiation). Only a small amount of each sample was available. Therefore the sample powder was deposited on flat zero-background substrate covered with a very thin film of Apiezon $M$ grease. This sample preparation also helps to prevent preferential orientation. The diffractograms were measured in the 2 theta range between 3 and $60^{\circ}$ with a step size of $0.04^{\circ}$ and a step time of $16 \mathrm{~s} / \mathrm{step}$. The qualitative analysis of the 
crystalline phases in the diffractograms was performed with the search/match tool of the DIFFRAC.EVA software (Bruker) using the PDF4+ database from the International Center for Diffraction Data.

\subsection{Raman spectrometer}

Each powdered sample was analyzed using a Horiba Jobin-Yvon Labram 300, confocal Raman spectrometer provided with an Olympus microscope. The spectrometer was interfaced to two lasers: the $514 \mathrm{~nm}$ line of a Spectra Physics model 164 argon ion laser and the $632.8 \mathrm{~nm}$ line of a Melles Griot He-Ne laser. Several spectra were recorded (between 4 and 10) for each of the samples. Since the samples could be damaged (combustion or phase transition) by local heating from the high laser energy focused on the sample, the laser power was varied between 0.4 and $40 \mathrm{~mW}$ with the green lasers $(514 \mathrm{~nm})$ and between 0.07 and $7 \mathrm{~mW}$ with the red laser, depending on the nature (sensitivity) of the particular sample under investigation. The recording time was varied between 10 and 150 seconds, depending on the input power selected. All spectra were obtained as an average of two spectra for each area analyzed.

The spectral baseline was corrected (where necessary) by fitting a polynomial function to the spectra. In order to do so, the spectral data were sampled (every 10 wave-number bins) and a polynomial function fit was performed for the first set of data. The polynomial background was iteratively evaluated. The very first polynomial background was estimated from a reduced selection of data points (one out of 10). Then, for each iterative step, a new polynomial was calculated to fit a new selection of data points (selected if the corresponding intensity was lower than the previous calculated background plus a $1 \%$ threshold of the maximum spectrum intensity). The iteration continued until a minimum was reached for the average deviation between the polynomial background and the selected data points.

\subsection{Total organic carbon and $\delta^{13} \mathrm{C}$ measurements}

TOC and $\delta^{13} \mathrm{C}_{\text {TOC }}$ were determined using a SerCon ANCA GSL elemental analyzer interfaced to a SerCon Hydra 20-20 continuous flow isotope ratio mass spectrometer. 


\subsection{Methylated pyrolysis-GC-MS}

The seven powdered desert varnish samples were analyzed with Py-GC-MS using a CDS 1000 pyroprobe interfaced to a Perkin Elmer Clarus 500 GC/MS system (lower cut off set at $\mathrm{m} / \mathrm{z}=50$ ). Approximately $10-20 \mathrm{mg}$ of sample was encapsulated in a clean quartz tube (previously heated until it was red in an oxidizing flame) and held in place with quartz wool plugs (formerly washed with a mixture of MeOH/DCM 1:1 v/v). $10 \mu \mathrm{L}$ of a solution of TMAH $(10 \% \mathrm{w} / \mathrm{v})$ was added to the samples just before the pyrolysis to prevent the complete thermal degradation of some compounds. The samples were inserted into the pyrolysis chamber for 15 seconds under helium flux prior the analyses. The samples were then pyrolyzed at $610{ }^{\circ} \mathrm{C}$ for 15 seconds. The pyrolysates (fragments formed during the pyrolysis) were then transferred (through a heated transfer line maintained at $310^{\circ} \mathrm{C}$ ) to a CP-Sil 5CB MS column (30 m x 0.25 $\mathrm{mm} \times 0.32 \mu \mathrm{m})$ maintained at $40{ }^{\circ} \mathrm{C}$ for 1.8 minutes. The $\mathrm{GC}$ temperature ramped to a final temperature of $310{ }^{\circ} \mathrm{C}$ (at the rate of $4{ }^{\circ} \mathrm{C}$ per minute) for 20 minutes.

The different fragments generated during the pyrolysis process were identified based on their mass spectra and their retention indices. The Amdis 2.71 software (developed by the National Institute of Standards and Technology, NIST) was used to further identify and integrate the peaks on the total ion current (TIC) chromatogram. The relative abundance of each identified compound was then determined from the ratio of the individual compound integrations to the summed integrations of all identified compounds, following Vancampenhout et al. (2008).

\section{Results}

Four analytical techniques previously proposed/included in planetary exploration missions were used to characterize 7 samples of desert varnish recovered from the Mojave Desert, USA. The results of the various analyses are presented as follows: X-ray diffraction, Raman spectroscopy, carbon content and stable carbon isotopes analysis, and finally the pyrolysis-gas chromatography-mass spectrometry. 


\subsection{X-ray diffraction}

X-ray diffractograms were collected for all samples and the results are shown in Figure 2. However, the identification of mineral patterns was not straightforward. Indeed, suitable samples for powder diffraction should contain tens of thousands of randomly oriented crystallites to obtain a pattern representative of all minerals present in the sample (Pecharsky and Zavalij, 2009). This was not the case for the samples studied here, which were generally composed of a few big grains (consistent with the grain size delivered by the ExoMars sample preparation and delivery system). This sampling statistics problem can lead to strongly biased relative intensity ratios or even to missing reflections, making it very difficult for the search algorithms to identify the minerals in the powder. Even when directing the search with filters or switching to an interactive approach selecting possible candidates directly from the database, it was not possible to index completely the experimental patterns of the desert varnish samples. Partial (and in some case tentative) identifications are proposed below.

For the samples DV1, DV2 and DV3, only quartz was readily identified as shown in Figure 2 (panel A, diffractograms a, b and c respectively). A weak peak at $44.5^{\circ}$ could be due to graphitic carbon, with the main reflection masked by the main reflection of quartz. The carbon peak is relatively broad, indicating a certain degree of amorphization, consistent with the results obtained by Raman spectroscopy as shown below.

For the samples CV1, CV2, CV3 and CV4, the diffractograms were more complex as shown in panel B of Figure 2 (diffractograms a, b, c and d respectively). Quartz was identified in samples CV2, CV3 and CV4 (weakly) but not CV1. The small and broader peak at $44.5^{\circ}$ was also interpreted as a sign for the presence of carbon in sample CV1, CV2 and CV4. The other peaks in the range 20-35 of the 2 theta values were attributed to plagioclase feldspars. However, it was hard to tell which plagioclase feldspars were present according to the data collected here. Albite (the sodium plagioclase feldspar) and anorthite (the calcium plagioclase feldspar) form a continuous solid solution (meaning that a continuous composition between albite and anorthite is allowed). Therefore the XRD pattern (position and intensity) will also vary with the degree of cation substitution (Goodyear, 1954). As an example, some of the peaks in the CV1 and CV4 patterns suggest an albite-like phase. On the pattern for sample CV4, the intense peaks located at $35.5^{\circ}$ and $49.9^{\circ}$ were attributed to hematite, while the presence of magnetite was suggested by the peak at $46.6^{\circ}$.

FIG. 2 


\subsection{Raman spectroscopy}

The Raman spectra obtained from several grains of both sets of samples are presented in Figures 3 and 4. Many different grains (varying in shape, size and color) could be distinguished for each of the samples considered (see Figure 1) so a representative selection are reported here. A list of minerals detected and the positions of the associated Raman bands are presented in Table 1.

\section{TABLE 1}

FIG. 3

The white/light grains were associated with the Raman signatures of tectosilicates such as quartz, plagioclase and microcline, for which the spectra are presented in Figure 3, panel A. Quartz (silicon dioxide) was mainly found to be present in the DV samples and on occasion in the CV set (supposedly due to the aeolian inclusion of sand grains in the desert varnish coating). Plagioclase (calcium-sodium feldspar) was found to be present in the samples from the Cady Valley site. This was consistent with our previous analyses of these samples using portable spectrometers, where quartz and plagioclase were found to be the main constituents of the rock substrata of both sets respectively (Malherbe et al., 2015). In addition, and using a confocal micro-spectrometer, microcline (the potassium feldspar) was found in the DV samples. This potassic feldspar can be distinguished from the sodico-calcic feldspars by confirming the presence of two bands at 475 and $453 \mathrm{~cm}^{-1}$. These were not observed, instead only a shoulder to the $508 \mathrm{~cm}^{-1}$ band (located at $480 \mathrm{~cm}^{-1}$ ) was recorded for the sodico-calcic feldspars. Three extra bands located at 813,749 and $266 \mathrm{~cm}^{-1}$ were also found to be present in the microcline spectrum compared to the plagioclase one as indicated in Figure 3A. Finally, for the samples from the Death Valley site, when the white grains appear shiny under the microscope, the Raman signal of muscovite (a phyllosilicate from the group of mica) was frequently observed.

The orange to reddish grains were found to be associated with the Raman signatures of iron minerals (Figure 3B) or carotenoids (Figure 4). For light orange grains, goethite, the iron oxihydroxide, was detected. (see Figure 3Ba). The darker red area on the samples was found to be comprised of hematite, the common iron oxide, often associated with orange-red grains. 
Several spectra of hematite obtained from the desert varnish are presented in Figure 3B (spectra b, $c$ and d). It is clear that several different structures of iron oxide were present. Some spectra corresponded to hematite $\left(\alpha-\mathrm{Fe}_{2} \mathrm{O}_{3}\right)$ exhibiting a Raman band at 224, 291, 408, 499 and 611 $\mathrm{cm}^{-1}$ and the second order band at $1317 \mathrm{~cm}^{-1}$ (not shown on Figure 3). Besides, some spectra corresponded to a mixture of hematite and magnetite $\left(\mathrm{Fe}_{3} \mathrm{O}_{4}\right)$ with a supplementary Raman band at $661 \mathrm{~cm}^{-1}$ and a loss in intensity of the hematite band at $1317 \mathrm{~cm}^{-1}$ which was sometime not observed (Faria et al., 1997).

The light orange grains are associated with inorganic compounds as well as carotenoids, which can be detected through their resonance Raman signal. Carotenoids were only detected using the $514 \mathrm{~nm}$ laser (which promotes the resonance effect). The carotenoid signal was always associated with a higher fluorescence background, resulting in a reduction in the quality of the spectra obtained (as illustrated in figure 4) and it was the only organic signal detected with the Raman microscope. Carotenoids, which comprise a long conjugated carbon chain (a sequence of alternative single and double carbon-carbon bonds), lead to a resonance Raman signal enhanced by a factor $10^{4}-10^{5}$ compared with a classical Raman signal. The resonance signal was detected at 1003, 1155 and $1512 \mathrm{~cm}^{-1}$ and was attributed to $\beta$-carotene (according to the position of the $1512 \mathrm{~cm}^{-1}$ which is dispersive as a function of the length of the conjugated carbon chain, Withnall et al., 2003). As shown in figure 4, when the signal of $\beta$-carotene was intense, the second order resonance Raman signal was also detected at 2647, 2292 and $2148 \mathrm{~cm}^{-1}$ and the weak feature around $2900 \mathrm{~cm}^{-1}$, which belongs to the stretching of the $\mathrm{C}-\mathrm{H}$ bonds, abundant in organic molecules, was also apparent.

FIG. 4

Darker grains were associated with the Raman signatures of carbon and various metallic oxides as shown in Figure 3. Anatase and rutile (see Figure 3C), two allotropic forms of titanium oxide, were found to be present in desert varnish (which is not surprising since they are common minerals on Earth). In the iron-rich samples (from the Cady Valley), pseudobrookite was present, which indicates that aeolian titanium (from the oxide) could have been incorporated during the coating formation. Pyrolusite, an oxide of manganese (IV) was often found in dark varnish grains. The spectrum of pyrolusite appears as a broad band centered around $650 \mathrm{~cm}^{-1}$ with a shoulder at around $550 \mathrm{~cm}^{-1}$ (see Figure 3D). The Raman signature of jacobsite, a mixed 
oxide of iron and manganese, was also recorded. Finally, the Raman signature of disordered carbonaceous material was recorded on several dark grains as well, sometimes in association with other minerals, as shown in Figure 3Dd where it appeared along with pyrolusite. The Raman spectrum of disordered carbonaceous material was composed of two broad bands: one localized at around $1580 \mathrm{~cm}^{-1}$ (the so called $G$ band, which is the only present band in the spectra recorded for the basal plane of graphite), the other at $1350 \mathrm{~cm}^{-1}$ (the so called $D$ band, which is only active when defects are present in the graphite lattice).

\subsection{Elemental analyses}

The total organic carbon (TOC) data and the stable carbon isotope composition (expressed as the depletion relative to PDB standard, $\delta^{13} \mathrm{C}$ ) are given in Table 2. The total organic carbon content of the sample varies between 0.10 and 0.41 percent in mass. According to a two-tailed t-test of the difference of the means between the two sets of desert varnish (at a $95 \%$ confidence interval, $\alpha=0.05$ ), the samples are part of the same population regarding the total organic carbon content. The stable isotopic carbon ratios were found to be $-24.0 \pm 0.2 \%$ for most of the desert varnish studied, except for the sample CV2 for which $\delta^{13} \mathrm{C}$ was found to be $-14.2 \%$.

\section{TABLE 2}

\subsection{Methylated pyrolysis-gas chromatography-mass spectrometry}

Consistent with the low level of organic carbon materials in the desert varnish determined via elemental analysis (see Table 2), the total ion current (TIC) measured for each desert varnish sample with pyrolysis was relatively low as shown in Figure 5. Nonetheless workable chromatograms were obtained and further analyzed. A total of 128 major compounds (contributing to $88 \%$ of the TIC) were putatively identified based on retention indices and NIST mass spectra library.

\section{FIG. 5}

Visualizing and interpreting so many components within a system is challenging, so to simplify the description of the samples, the organic compounds were classified into 5 groups 
according to their chemical function/structure: alkanes (AlkA), alkenes (AlkE), fatty acid methyl esters (FAME), monocyclic aromatic hydrocarbons (Ar) and polycyclic aromatic hydrocarbons (PAH). The relative amount of each group for the 7 samples is summarized in Figure 6, where the error bars represent the standard deviation of the TIC percentage obtained for the 7 samples. The compositions determined for each sample are given in Table 3.

FIG. 6

\section{TABLE 3}

FAMEs (derived from fatty acids methylated during the pyrolysis in presence of TMAH) were the main contributors to the TIC for all the samples interrogated. Typically, the ion chromatogram at $\mathrm{m} / \mathrm{z}=74$ (characteristic of FAMEs) was dominated by the peaks belonging to short- chain FAMEs with an even number of carbon atoms (in the range $\mathrm{C}_{8}-\mathrm{C}_{18}$ ), especially $\mathrm{C}_{16}$ (palmitic acid). Short-chain FAMEs with an odd number of carbon atoms (in the range $\mathrm{C}_{7}-\mathrm{C}_{17}$ ) were also observed for samples containing more FAMEs overall, notably samples DV1, DV3, CV2 and CV4. In addition, unsaturated palmitoleic acid methyl ester (C16:1) was detected for DV1, DV3 CV2 and CV4, and unsaturated oleic acid methyl ester (C18:1) was detected for DV1, DV3 and CV2. For these compounds, the position of the double $\mathrm{C}=\mathrm{C}$ bond was difficult to determine based only on the retention index (1886 and 2086 respectively). Finally, iso- and anteiso- FAMEs were detected. In particular anteiso- $\mathrm{C}_{15}$ FAME was detected in DV1, DV3, CV2 and CV4, but anteiso-C ${ }_{17}$ FAME was only detected in DV1 and DV3.

The second most common chemical group observed in the samples was the alkenes (AlkE). $97 \%$ of the alkenes detected were $n$-alkenes unsaturated in position $\mathrm{C}_{1}$. They were found in the range between $\mathrm{C}_{10}$ and $\mathrm{C}_{18}$, often dominated by the members in the range $\mathrm{C}_{10}$ and $\mathrm{C}_{16}$. This trend was followed by the $n$-alkane (AlkA), which represent the $4^{\text {th }}$ contributive group to the TIC. Alkanes were detected in the range $\mathrm{C}_{7}-\mathrm{C}_{17}$ and dominated by the n-pentadecane $\left(\mathrm{C}_{15} \mathrm{H}_{32}\right)$.

The third and fourth most frequently observed chemical groups encompass the aromatic molecules: the monocyclic aromatic hydrocarbons (Ar) and polycyclic aromatic hydrocarbons (PAH) respectively. The PAH were detected weakly only in DV2, DV3, CV2, CV3 and CV4. They were $1 \mathrm{H}$-indene derivatives (mainly) and methylated naphthalene. The monoaromatics 
members can be further divided into 3 sub-groups: poly-methylated benzenes (Ar1), linear alkyl benzenes ( $\mathrm{LAB})$ and branched alkyl benzenes $(\mathrm{BAB})$. The $\mathrm{BAB}$ were the dominant aromatic compounds ( $66 \%$ of the aromatic compounds detected), comprising a complete series of 1dialkyl benzene with a number of alkyl carbon between 10 and 13 in total (distributed on two carbon chains). LAB represented only $\sim 12 \%$ of the aromatic compounds and comprised the series between the propyl-benzene and the dodecyl-benzene. Finally poly-methylated benzene contributed to $\sim 23 \%$ of the aromatics.

\section{Discussion}

Here we have presented a thorough characterization of some desert varnish specimens, which are considered to be potential Martian analogue samples. As such, their analysis can inform the development (and operation) of instrumentation for future exploration missions on Mars. In particular, the potential habitability of these samples (i.e. the capability to host life) was investigated using three analytical techniques that have been proposed for future space missions (or are implemented on current missions). The geological components of the desert varnish samples were identified using XRD and micro-Raman spectroscopy, while the nature of the organic matter associated with the samples was assessed using TMAH py-GC/MS.

The XRD technique was found to be sensitive only to the main mineral components of the desert varnish powders (compromised by the limited material available). Indeed, only welldefined crystalline phases such as quartz and feldspar were readily detected using this technique. The use of micro-Raman spectroscopy enabled confirmation of a broad range of mineral constituents within the desert varnish coatings interrogated in this study. According to the Raman data, the desert varnish coatings of both sets of samples (from the Death Valley or the Cady valley sites) comprise quartz, plagioclase, haematite, goethite and $\mathrm{TiO}_{2}$, which is in agreement with our previous study of these samples using flight representative miniaturized spectrometers (Malherbe et al., 2015). In addition, by using the confocal micro-spectrometer, some additional minerals were detected. Pyrolusite (and to a lesser extent jacobsite), a manganese oxide, was detected, confirming that the samples were actually covered with a desert varnish formation, which is typically considered to comprise manganese oxide together with iron oxide and clay (Dorn, 2008). The detection of such minerals was however only feasible using confocal spectrometers. This reflects the fact that the confocal instruments reduce the fluorescence background of the spectra (the confocal pinhole rejecting the light which is out of 
focus). In addition, the microscope coupled to the spectrometer reduced the laser spot diameter to a few microns ( $\sim 2 \mu \mathrm{m}$ in the present study), and thereby the volume of sample analyzed was reduced $\left(\sim 4 \mu \mathrm{m}^{3}\right)$. As a direct consequence, the back absorption of the Raman signal by darker samples was also decreased, which enabled the ready detection of hematite using a green laser (that was less straightforward using a miniaturized instrument; Malherbe et al., 2015).

The main constituents of the varnish detected with Raman spectroscopy were quartz and plagioclase which were identified for the DV and CV sets of samples respectively. This was expected as they represent the main constituents of the rock substrata of the samples (Malherbe et al., 2015). In addition to plagioclase, quartz grains were also found in the varnish coating for the samples from the Cady Valley (most probably, those grains were incorporated in the varnish following aeolian supply). This would be logical because the samples were retrieved next to a sand deposit originating from a former sea basin in a location swept by wind. For the samples obtained from Death Valley, microcline (potassic feldspar) was also found, as was muscovite (a mica from the group of phyllosilicate). These two minerals, together with the plagioclase (also a feldspar) are particularly relevant to the potential habitability of the desert varnish. Indeed many feldspar rocks have been reported to be colonized by various microorganisms on Earth (Edwards et al., 2011). Muscovite (a phyllosilicate such as montmorillonite) presents a lamellar structure where each aluminosilicate layer (negatively charged) is separated by potassium cations (positively charged). They provide a possible source of water in arid environments since molecules of water can be accommodated inside the layers (Hatch et al., 2012). All of the Raman spectra indicate well crystallized silicate phases and no evidence of amorphous glassy phases or newly formed silicates were observed. This seems to indicate that the abiotic formation process (suggested by Perry (Perry et al., 2006)) involving baking of silicic acid on the substrata does not apply for the samples considered here. However, the insertion of quartz grains in the coatings of the Cady Valley samples does suggest some aeolian mineral input (Dorn, 2008).

The detection of goethite indicates that the desert varnish coatings were formed relatively recently on the rock substrata. Indeed, goethite tends to evolve to hematite with time via dehydration (the transformation of goethite into hematite does not necessitate significant reorganization of the anionic sublattice and therefore can occur even at low temperature by topotactic transformation (Cudennec and Lecerf, 2005)). Small amounts of water can then be released during the transformation, enabling microorganisms to survive in arid locations such as the Mojave Desert. Detection of hematite was also important since it was recognized for 
potential long-term preserving microfossils (Allen et al., 2001), and therefore possible biomarkers. The hematite spectra reported here often exhibit an extra band at $660 \mathrm{~cm}^{-1}$ that is attributed to magnetite (Edwards et al., 2001). This band is also present in the spectra of disordered hematite that could result from heated goethite (Faria and Lopes, 2007). However, great care has been taken to avoid any laser induced phase transition. Indeed, spectra were discarded if any change in the relative intensities was noticed during the recording process (and analyses repeated using a fresh non-burned area, after decreasing the laser power). In addition, after recording the spectrum of goethite several times, it was apparent that there was no evidence of spectral evolution in the data. Consequently, it is clear that the band at $660 \mathrm{~cm}^{-1}$ (in the spectra of hematite) is not an experimental artefact, and that it does, in fact, indicate the presence of magnetite or disordered hematite. In the context of planetary exploration, this can indicate weak crystallization, a weathering process or a biodegradation of the former hematite present (Faria and Lopes, 2007). Finally, the presence of magnetite (confirmed by XRD) in such samples could be linked to a possible reduction of some iron cations of hematite by organic molecules (Konhauser and Riding, 2012). The identification of magnetite with hematite on Mars was seen as a proof that redox coupling can take place, highlighting a possible route for energy processing by chemoautotrophic microorganisms (Grotzinger et al., 2014).

Beside mineral substances, Raman data also revealed the presence of carbon materials such as disordered carbonaceous material (detected with the 514 and $633 \mathrm{~nm}$ lasers) and $\beta$ carotene (only detected with the 514 nm laser). The latter is a compound excreted by a range of microorganisms, such as cyanobacteria, particularly when they adapt to extreme environments. Its detection implies that living organisms were possibly associated with the desert varnish samples analyzed here. $\beta$-carotene was either part of the molecular protective pigments excreted by living bacteria present on the desert varnish samples or $\beta$-carotene was preserved within the geological matrix constituting the desert varnish (and therefore indicative of a recent past bacterial activities). Both hypothesis are in agreement with the identification by Py-GC-MS of fatty acids specific of bacteria. In either cases, the detection of $\beta$-carotene by Raman spectroscopy can only indicate a quite recent bacterial activity. Indeed, under typical atmospheric conditions, $\beta$-carotene is not likely to be preserved over an extended period of time as the polyene will diagenetically transform into $\beta$-carotane or isoprenoid fragments (French et al., 2015; Marshall and Olcott Marshall, 2010). Nevertheless, $\beta$-carotene was reported as a preserved bacterial biomarker in sediments of 600 years old (Lepot et al., 2014). It should be noted that a highly reduced laser power on the sample was required to detect $\beta$-carotene in the 
desert varnish powders. Under the microscope, the spectrum of $\beta$-carotene evolved to the spectrum of disordered carbonaceous material if the irradiance was higher than $10 \mathrm{~kW} \mathrm{~cm}-2$ (which is ten times the irradiance of the ExoMars-RLS instrument, Lopez-Reyes et al., 2013). However, no organic compound other than $\beta$-carotene was detected using Raman spectroscopy with the samples of desert varnish. This is not surprising since the cross section of organic molecules is lower than for inorganic compounds, and only a small amount of organic compounds were revealed by the Py-GC-MS. Disordered carbonaceous material was often detected on the samples by Raman spectroscopy and could have resulted from either a direct aeolian deposition of carbon dusts onto the desert varnish during its formation (in which case it is not a biomarker) or the degradation of organic compounds from decaying dead microorganisms which colonized the desert varnish in the past (in which case it is sometime viewed as a possible biomarker in the context of searching for extraterrestrial forms of life). However, Raman spectroscopy is not a suitable technique for differentiating between biogenic and abiogenic disordered carbonaceous material (Pasteris and Wopenka, 2003). Other analytical methods should be considered to describe the structure and the origin of the carbonaceous material in more detail.

The reference method for analysis of carbon is mass spectrometry coupled to gas chromatography and we applied that technique to characterize the nature and content of the organic compounds in the samples. The carbon contents (assimilated to the total organic carbon since no carbonate was detected in the samples) were actually very low, lower than the typical average TOC content for lacustrine sediments in deep oceans ( 0.5\%) (Seiter et al., 2004), and lower than the TOC values measured for soils in arid locations in South Africa ( 0.8\%) (Carr et al., 2013). Such low values of carbon content suggest that not much organic material was present in/on the desert varnish coatings interrogated during this study. The stable carbon isotope ratios measured for the seven samples of desert varnish were in agreement with previous data reported for other similar samples (Dorn and DeNiro, 1985; Dorn et al., 1987; Perry and Kolb, 2004). Most of the $\delta^{13} \mathrm{C}$ values were consistent with organic matter derived from $\mathrm{C}_{3}$ photosynthetic plants, which could have been processed by microorganisms that were present on the desert varnish. The desert varnish samples studied here could then enclose some old organic matter. It must however be stressed that the values reported here were obtained for the entire varnish coating and that some influence of the underlying rock materials cannot be ruled out. In addition, a $\delta^{13} \mathrm{C}$ value of $-24.8 \%$ from Mojave Desert soil has been reported before (Navarro-Gonzáles et al., 2006), which is quite close to the values obtained here. 
The Py-GC-MS measurements revealed no clear variation between the two sets of samples. The samples were all dominated by FAMES, $n$-alkanes and $n$-alkanes and branched alkyl benzenes. This suite of pyrolysis products was consistent with a bacterial origin of the organic matter found in the samples of desert varnish. The major compounds were the fatty acid methyl esters (FAME). Although FAMEs could have been present in the samples before the pyrolysis, they are most-likely mainly formed during the pyrolysis because of the tetramethylammonium hydroxide (Challinor 1996). Only short-chain FAMEs were observed $\left(<\mathrm{C}_{18}\right)$, which suggested that the organic matter originated from bacterial activities. Indeed, the saturated fatty acids (constituting the lipids of the cell membranes) are typically found in the range $\mathrm{C}_{14}-\mathrm{C}_{18}$ for bacteria, in the range $\mathrm{C}_{16}-\mathrm{C}_{26}$ for algae and in the range $\mathrm{C}_{28}-\mathrm{C}_{36}$ for plants (Jetter et al., 2006). The absence of the long chain FAMEs is good sign that leaf waxes of local vegetation are not making a substantial contribution to the Py-GC-MS data. Iso, anteiso and some unsaturated fatty acid derivatives were also proposed as specific biomarkers for bacteria (Schelble 2005, Wanglu 2005, Geffroy-Rodier 2009). Iso- and anteiso- isomers of $\mathrm{C}_{15}$ and $\mathrm{C}_{17}$ FAMEs were identified in the chromatograms of several samples (sometimes with an intensity below the quantification limit, but still readily identified on the $\mathrm{m} / \mathrm{z}=74$ chromatogram). The presence of these isomers again suggests a bacterial processing/origin for the organic matter in the samples. Additionally, short chain length $n$-alkanes and $n$-alkenes were also detected in the samples. Again they could have been present in the samples before the pyrolysis, but are likely to be produced by decarboxylation during the pyrolysis (Hartgers et al., 1995). The anticorrelation observed between the FAME and the AlkA and AlkE (data not shown) suggests that alkanes and alkenes detected during Py-GC-MS mainly originated from fatty acids that were present in the samples before the pyrolysis.

The detection of aromatic compounds is harder to interpret, especially the linear alkyl benzenes (LAB) and the branched alkyl benzenes (BAB). Short LAB (up to $n-\mathrm{C}_{4}$ ) are found in kerogen, but the chromatograms obtained for the samples of desert varnish are not consistent with the ion current intensity profile obtained for kerogens (Gonzalez-Vila et al., 2001, Jia and Peng, 2005). Alkylbenzenes may also derive from a linear precursor, such as long fatty acids undergoing cyclization and a subsequent aromatization during the pyrolysis process, especially from salts of fatty acids (Saiz-Jimenez, 1994). Observation of LAB and BAB series could be the result of a derivatization of primary organic molecules during the pyrolysis. $\beta$-carotene, which was detected by Raman spectroscopy, was not detected during the Py-GC-MS analyses, 
indicating that it was not preserved during the pyrolysis. The polyene could very well have undergone cyclization during the pyrolysis process to lead to $\mathrm{LAB}$ or $\mathrm{BAB}$.

The products of Py-GC-MS can be quite different from the organic compounds that were originally in the sample. Indeed, the nature of the mineral substrate can substantially influence the nature of the organic compounds that are produced during a flash pyrolysis process (Stalport et al., 2012). Iron oxide, which was often detected on the desert varnish samples, could act as a catalyst for the decarboxylation of fatty acids during pyrolysis as suggested by Yoshioka et al. (2005). Iniguez et al. (2009) reported that oxygen atoms and hydroxyl radicals (two strong oxidative species) are released during a thermal reduction of iron (III) oxide and a thermal dehydration of silicates respectively, at temperatures below $600^{\circ} \mathrm{C}$. These active chemicals can lead to decarboxylation and oxidation of the organic matter present in the sample. Degradation of organic compounds into $\mathrm{CO}_{2}$ and $\mathrm{H}_{2} \mathrm{O}$ can even lead to a lack of detection of any organic molecule (Navarro-Gonzalez et al., 2006). In addition, clays, which are also present in desert varnish, have been reported to induce aromatization of organic matter during pyrolysis (Faure et al., 2006). In the context of searching for evidence of life in a potential biogeological sample, describing the geological matrix of the sample together with the associated organic matter is therefore considered to be critical when using py-GC/MS or analogous methods to characterize the organic material in a sample. Here, we affirm an analytical strategy combining Raman spectroscopy (a non-destructive technique which enables the mineral characterization of the samples, and the detection of highly Raman active biomarkers such as $\beta$-carotene) and Py-GC-MS (a destructive technique, which may enable unique insights into the nature of the organic compounds, despite potential limitations of the techniques when applied in isolation (Marshall et al., 2007).

\section{Conclusion}

The habitable nature of desert varnish samples (recovered from the Mojave Desert) have been described using data obtained with a combination of four different analytical methods that have been proposed (or, in some cases, already used) for planetary exploration missions. XRD and Raman spectroscopy were effective in non-destructively determining the mineralogical constituents of the desert varnish comprising silicates, muscovite clay, iron, manganese and titanium oxides and iron hydroxide. RS was found to be more efficient than XRD in the description of the desert varnish samples. Raman spectroscopy also enabled the detection of $\beta$ carotene. The nature and content of organic matter in the samples were further interrogated by 
methylated Py-GC-MS which gave unique insight into the composition of the samples. This organic matter was for the most part dominated by fatty acids and it concluded that it is likely to originate from a bacterial activity. The absence of $\beta$-carotene in the pyrolysates (at least with the present measurement conditions) highlights a potential limitation of the pyrolysis extraction method leading to the fragmentation of thermo-sensitive molecules. Possible interference of the geological substrate on the resulting pyrolysis products was discussed and requires further assessment. Ongoing work focuses on the complementarity of Raman spectroscopy and the PyGC-MS, especially in terms of detectability of specific biomarkers such as $\beta$-carotene and extraction and concentration of organic compounds would be envisaged.

\section{Acknowledgement}

C.M., I.B.H., R.I. and H.G.M.E acknowledge support from the UK Space Agency in the UK and C.M. acknowledges the support of the Department of Chemistry at the University of Liège. A.S.C. and A.B. acknowledge support from the Department of Geology at the University of Leicester.

\section{Author Disclosure Statement}

No competing financial interests exist.

\section{References}

Allen, C. C., Westall, F., and Schelble, R. T. (2001) Importance of a Martian Hematite Site for Astrobiology. Astrobiology, 1(1), 111-123.

Brinckerhoff, W. B., Pinnick, V. T., van Amerom, F. H. W., Danell, R. M., Arevalo, R. D., Atanassova, M. S., Xiang, L., Mahaffy, P. R., Cotter, R. J., Goesmann, F., Steininger, H. (2013) Mars Organic Molecule Analyzer (MOMA) mass spectrometer for ExoMars 2018 and beyond. 2013 IEEE Aerospace Conference, 1-8. 
Carr, A. S., Boom, A., Chase, B. M., Meadows, M. E., Roberts, Z. E., Britton, M. N., and Cumming, A. M. J. (2013) Biome-scale characterisation and differentiation of semi-arid and arid zone soil organic matter compositions using pyrolysis-GC/MS analysis. Geoderma, 200201, 189-201.

Challinor, J. M. (1996) A rapid pyrolysis derivatization gas chromatography-mass spectrometry method for profiling of fatty acids in trace quantities of lipids. J. Anal. Applied Pyrolysis, 37(96), 185-197.

Chyba, C., and Sagan, C. (1992) Endogenous production, exogenous delivery and impact-shock synthesis of organic molecules: an inventory for the origins of life. Nature, 355, 125-132.

Cudennec, Y., and Lecerf, A. (2005) Topotactic transformations of goethite and lepidocrocite into hematite and maghemite. Solid State Sciences, 7(5), 520-529.

de Faria, D. L. A., and Lopes, F. N. (2007) Heated goethite and natural hematite: Can Raman spectroscopy be used to differentiate them? Vibrational Spectroscopy, 45(2), 117-121.

de Faria, D. L. A., Silva, S. V., and de Oliveira, M. T. (1997) Raman microspectroscopy of some iron oxides and oxyhydroxides. Journal of Raman Spectroscopy, 28(2), 873-878.

DiGregorio, B. E. (2002) Rock varnish as a habitat for extant life on Mars. Proc. SPIE 4495.

Dorn R. I. (2008) Rock Varnish. In: Geochemical Sediments and Landscapes, edited by D.J. Nash and S.J. McLaren, Blackwell Publishing, Malden, MA, pp 246-297.

Dorn, R. I. (2007) Baking black opal in the desert sun: The importance of silica in desert varnish: COMMENT AND REPLY: COMMENT. Geology, 35(1), e122-e123. 
Dorn, R. I., and DeNiro, M. J. (1985) Stable Carbon Isotope Ratios of Rock Varnish Organic Matter: A New Paleoenvironmental Indicator. Science, 227(4693), 1472-1474.

Dorn, R. I., DeNiro, M. J., and Ajie, H. O. (1987) Isotopic evidence for climatic influence on alluvial-fan development in Death Valley, California. Geology, 15(2), 108.

Edwards, H. G. M. (2007) Question 2: Raman spectroscopic approach to analytical astrobiology: The detection of key biomolecular markers in the search for life. Origins of Life and Evolution of Biospheres, 37(4-5), 335-339.

Edwards, H. G. M., Farwell, D. W., de Faria, D. L. A., Monteiro, A. M. F., Afonso, M. C., De Blasis, P., and Eggers, S. (2001) Raman spectroscopic study of 3000-year-old human skeletal remains from a sambaqui, Santa Catarina, Brazil. Journal of Raman Spectroscopy, 32(1), 1722.

Edwards, H. G. M., Hutchinson, I. B., Ingley, R., Parnell, J., Vítek, P., and Jehlička, J. (2013) Raman Spectroscopic Analysis of Geological and Biogeological Specimens of Relevance to the ExoMars Mission. Astrobiology, 13(6), 543-549.

Edwards, H. G., Hutchinson, I. B., Ingley, R., Waltham, N. R., Beardsley, S., Dowson, S., and Woodward, S. (2011) The search for signatures of early life on Mars: Raman spectroscopy and the Exomars mission. Spectroscopy Europe, 23(1), 6.

Ehrenfreund, P., and Charnley, S. B. (2000) Organic Molecules in the Interstellar Medium, Comets, and Meteorites: A Voyage from Dark Clouds to the Early Earth. Annual Review of Astronomy and Astrophysics, 38, 427.

Ehrlich, H. L., and Newman, D. K. (2009) In: Geomicrobiology (5th ed.), Taylor and Francis group, pp 37-55. 
Final version available at: $\underline{\text { http://online.liebertpub.com/doi/abs/10.1089/ast.2016.1512 }}$

ExoMars mission (2015) ExoMars mission 2018. Available online at http://exploration.esa.int/mars/48088-mission-overview/

Fairén, A. G., Davila, A. F., Lim, D., Bramall, N., Bonaccorsi, R., Zavaleta, J., Uceda, E.R., Stoker, C., Wierzchos, J., Dohm, J.M., Amils, R., Andersen, D., and McKay, C.P. (2010) Astrobiology through the Ages of Mars: The Study of Terrestrial Analogues to Understand the Habitability of Mars. Astrobiology, 10(8), 821-843.

Faure, P., Schlepp, L., Mansuy-Huault, L., Elie, M., Jardé, E., and Pelletier, M. (2006) Aromatization of organic matter induced by the presence of clays during flash pyrolysis-gas chromatography-mass spectrometry (PyGC-MS): A major analytical arteifact. Journal of Analytical and Applied Pyrolysis, 75(1), 1-10.

Fisk, M. R., and Giovannoni, S. J. (1999) Sources of nutrients and energy for a deep biosphere on Mars. Journal of Geophysical Research, 104(E5), 11805.

French, K. L., Rocher, D., Zumberge, J. E. and Summons, R. E. (2015) Assessing the Distribution of Sedimentary C40 Carotenoids through Time. Geobiology, 13(2), 139-51.

Geffroy-Rodier, C., Grasset, L., Sternberg, R., Buch, a., and Amblès, a. (2009) Thermochemolysis in search for organics in extraterrestrial environments. Journal of Analytical and Applied Pyrolysis, 85(1-2), 454-459.

Gonzalez-Vila, F. J., Amblès, A., del Río, J. C., and Grasset, L. (2001) Characterisation and differentiation of kerogens by pyrolytic and chemical degradation techniques. Journal of Analytical and Applied Pyrolysis, 58-59(0), 315-328.

Goodyear, J. (1954) The Identification and Determination of Plagioclase Felspars by the X-ray Powder Method. Mineralogical Magazine, 30(224), 306-326. 
Grotzinger, J. P., Sumner, D. Y., Kah, L. C., Stack, K., Gupta, S., Edgar, L., Rubin, D., Lewis, K., Schieber, J., Mangold, N., Milliken, R., Conrad, P.G., DesMarais, D., Farmer, J., Siebach, K., Calef, F., Hurowitz, J., McLennan, S.M., Ming, D., Vaniman, D., Crisp, J., Vasavada, A., Edgett, K.S., Malin, M., Blake, D., Gellert, R., Mahaffy, P., Wiens, R C., Maurice, S., Grant, J.A., Wilson, S., Anderson, R.C., Beegle, L., Arvidson, R., Hallet, B., Sletten, R.S., Rice, M., Bell, J., Griffes, J., Ehlmann, B., Anderson, R.B., Bristow, T.F., Dietrich, W.E., Dromart, G., Eigenbrode, J., Fraeman, A., Hardgrove, C., Herkenhoff, K., Jandura, L., Kocurek, G., Lee, S., Leshin, L.A., Leveille, R., Limonadi, D., Maki, J., McCloskey, S., Meyer, M., Minitti, M., Newsom, H., Oehler, D., Okon, A., Palucis, M., Parker, T., Rowland, S., Schmidt, M., Squyres, S., Steele, A., Stolper, E., Summons, R., Treiman, A., Williams, R., Yingst, A., and Team, MSL Science (2014) A Habitable Fluvio-Lacustrine Environment at Yellowknife Bay, Gale Crater, Mars. Science, 343(6169), 1242777-1242777.

Hartgers, W. A., Sinninghe Damsté, J. S., and de Leeuw, J. W. (1995) Curie-point pyrolysis of sodium salts of functionalized fatty acids. Journal of Analytical and Applied Pyrolysis, 34(94), $191-217$.

Hatch, C. D., Wiese, J. S., Crane, C. C., Harris, K. J., Kloss, H. G., and Baltrusaitis, J. (2012) Water Adsorption on Clay Minerals As a Function of Relative Humidity: Application of BET and Freundlich Adsorption Models. Langmuir, 28(3), 1790-1803.

Hutchinson, I. B., Ingley, R., Edwards, H. G. M., Harris, L., McHugh, M., Malherbe, C., and Parnell, J. (2014) Raman spectroscopy on Mars: identification of geological and bio-geological signatures in Martian analogues using miniaturized Raman spectrometers. Philosophical Transactions of the Royal Society A: Mathematical, Physical and Engineering Sciences, 372(2030), 20140204-20140204. 
Iñiguez, E., Navarro-González, R., De La Rosa, J., Ureña-Núñez, F., Coll, P., Raulin, F., and McKay, C.P. (2009) On the oxidation ability of the NASA Mars-1 soil simulant during the thermal volatilization step: Implications for the search of organics on Mars. Geophysical Research Letters, 36(21), 1-5.

Jehlička, J., and Oren, A. (2013) Use of a handheld Raman spectrometer for fast screening of microbial pigments in cultures of halophilic microorganisms and in microbial communities in hypersaline environments in nature. Journal of Raman Spectroscopy, 44(9), 1285-1291.

Jehlička, J., Culka, A., Vandenabeelee, P., and Edwards, H. G. M. (2011) Critical evaluation of a handheld Raman spectrometer with near infrared $(785 \mathrm{~nm})$ excitation for field identification of minerals. Spectrochimica Acta Part A: Molecular and Biomolecular Spectroscopy, 80(1), $36-40$.

Jehlicka, J., Edwards, H. G. M., and Culka, A. (2010) Using portable Raman spectrometers for the identification of organic compounds at low temperatures and high altitudes: exobiological applications. Philosophical Transactions of the Royal Society A: Mathematical, Physical and Engineering Sciences, 368(1922), 3109-3125.

Jetter, R., Kunst, L., and Samuels, A. L. (2006) In: Biology of the Plant Cuticle, edited by M. Riederer and C. Müller, Blackwell Publishing, Oxford, UK, pp 145-181.

Jia, W., and Peng, P. (2005) Molecular structure of kerogens from source rocks of the Tarim Basin: A study by Py-GC-MS and methylation-Py-GC-MS. Science in China Series D, 48(3), 313.

Johnson, A. P., Cleaves, H. J., Dworkin, J. P., Glavin, D. P., Lazcano, A., \& Bada, J. L. (2008) The Miller volcanic spark discharge experiment. Science (New York, N.Y.), 322(5900), 404. 
Jorge Villar, S. E., and Edwards, H. G. M. (2006) Raman spectroscopy in astrobiology. Analytical and Bioanalytical Chemistry, 384(1), 100-113.

Jorge Villar, S., Edwards, H., and Benning, L. (2006) Raman spectroscopic and scanning electron microscopic analysis of a novel biological colonisation of volcanic rocks. Icarus, 184(1), 158-169.

Konhauser, K., and Riding, R. (2012) In: Fundamentals of Geobiology, edited by A.H. Knoll, D.E. Canfield and K.O. Konhauser, John Wiley \& Sons, pp. 105-130.

Lanza, N. L., Fischer W. W., Wiens, R. C., Grotzinger J., Ollila, A. M., Cousin, A., Anderson, R. B., Clark, B. C., Gellert, R., Mangold, N., Maurice, S., Le Mouélic, S., Nachon, M., Schmidt, M., Berger, J., Clegg, S.M., Forni, O., Hardgrove, C., Melikechi, N., Newsom, H.E., and Sautter, V. (2014) High manganese concentrations in rocks at Gale crater, Mars. Geophysical Research Letters, 41, 5755-5763.

Lepot, K., Compere, P., Gerard, E., Namsaraev, Z., Verleyen, E., Tavernier, I., Hodgson, D. A., Vyverman, W., Gilbert, B., Wilmotte, A., and Javaux, A. J. (2014) Organic and Mineral Imprints in Fossil Photosynthetic Mats of an East Antarctic Lake. Geobiology, 12(5), 424-50.

Lopez-Reyes, G., Rull, F., Venegas, G., Westall, F., Foucher, F., Bost, N., Sanz, A., CataláEspí, A., Vegas, A., Hermosilla, I., Sansano, A., and Medina, J., (2013) Analysis of the scientific capabilities of the ExoMars Raman Laser Spectrometer instrument. European Journal of Mineralogy, 25(5), 721-733.

Malherbe, C., Ingley, R., Hutchinson, I., Edwards, H., Carr, A. S., Harris, L., and Boom, A. (2015) Biogeological Analysis of Desert Varnish Using Portable Raman Spectrometers. Astrobiology, 15(6), 442-452. 
Mancinelli, R. L. and White, M. R. (1996) Mineralogical analysis of desert varnish by DTA/GC: applicability to the exobiology of Mars. Lunar \& Planetary Sciences, 27, 2.

Marinangeli, L., Hutchinson, I., Baliva, A., Stevoli, A., Ambrosi, R., Critani, F., Delhez, R., Scandelli, L., Holland, A., Nelms, N., and Mars-Xrd Team (2007) An European XRD/XRF instrument for the ExoMars Mission. In Lunar and Planetary Science Conference (Vol. 38, p. 1322).

Marnocha, C. L., and Dixon, J. C. (2013) Bacterial communities in Fe/Mn films, sulphate crusts, and aluminium glazes from Swedish Lapland: implications for astrobiology on Mars. International Journal of Astrobiology, 12(04), 345-356.

Marshall, C. P., and Olcott Marshall, A. (2010) The Potential of Raman Spectroscopy for the Analysis of Diagenetically Transformed Carotenoids. Philosophical transactions. Series A, Mathematical, physical, and engineering sciences, 368(1922), 3137-44.

Marshall, C. P., Love, G. D., Snape, C. E., Hill, A. C., Allwood, A. C., Walter, M. R., ... Summons, R. E. (2007) Structural characterization of kerogen in 3.4 Ga Archaean cherts from the Pilbara Craton, Western Australia. Precambrian Research, 155(1-2), 1-23.

Mellon, M. T., Arvidson, R. E., Sizemore, H. G., Searls, M. L., Blaney, D. L., Cull, S., Hecht, M.H., Heet, T.L., Keller, H.U., Lemmon, M.T., Markiewicz, W.J., Ming, D.W., Morris, R.V., Pike, W.T., and Zent, A.P. (2009) Ground ice at the Phoenix Landing Site: Stability state and origin. Journal of Geophysical Research, 114(12), E00E07.

Miralles, I., Jorge-Villar, S. E., Cantón, Y., and Domingo, F. (2012) Using a Mini-Raman Spectrometer to Monitor the Adaptive Strategies of Extremophile Colonizers in Arid Deserts: 
Relationships Between Signal Strength, Adaptive Strategies, Solar Radiation, and Humidity. Astrobiology, 12(8), 743-753.

NASA Mars 2020 (2014) NASA Announces Mars 2020 Rover Payload to Explore the Red Planet as Never Before, NASA's Mars Exploration Program (MEP), Washington, DC. Available online at http://nasa.gov/press/2014/july/nasa-announces-mars-2020-rover-payloadto-explore-the-red-planet-as-never-before.

NASA Water on Mars (2015) NASA Confirms Evidence That Liquid Water Flows on Today's Mars, NASA's Mars Exploration Program (MEP), Washington, DC. Available online at https://www.nasa.gov/press-release/nasa-confirms-evidence-that-liquid-water-flows-ontoday-s-mars.

Navarro-Gonzalez, R. (2003) Mars-Like Soils in the Atacama Desert, Chile, and the Dry Limit of Microbial Life. Science, 302(5647), 1018-1021.

Navarro-González, R., Navarro, K. F., de la Rosa, J., Iñiguez, E., Molina, P., Miranda, L. D., Morales, P., Cienfuegos, E., Coll, P., Raulin, F., Amils, R., and McKay, C.P. (2006) The limitations on organic detection in Mars-like soils by thermal volatilization-gas chromatography-MS and their implications for the Viking results. Proceedings of the National Academy of Sciences of the United States of America, 103(44), 16089-16094.

Ojha, L., Wilhelm, M. B., Murchie, S. L., McEwen, A. S., Wray, J. J., Hanley, J., Massé, M., Chojnacki, M. (2015) Spectral evidence for hydrated salts in recurring slope lineae on Mars. Nature Geoscience, 8(11), 829-832.

Pasteris, J. D., and Wopenka, B. (2003) Necessary, but not sufficient: Raman identification of disordered carbon as a signature of ancient life. Astrobiology, 3(4), 727-738. 
Pecharsky, V. K., and Zavalij, P. Y. (2009) In: Fundamentals of Powder Diffraction and Structural Characterization of Materials, Springer, New York.

Perry, R. S., and Kolb, V. M. (2004) Biological and organic constituents of desert varnish: review and new hypotheses. In Optical Science and Technology, SPIE's 48th Annual Meeting, pp. 202-217.

Perry, R. S., Engel, M. H., Botta, O., and Staley, J. T. (2003) Amino acid analyses of desert varnish from the Sonoran and Mojave Deserts. Geomicrobiology Journal, 20, 427-438.

Perry, R. S., Lynne, B. Y., Sephton, M. A., Kolb, V. M., Perry, C. C., and Staley, J. T. (2006) Baking black opal in the desert sun: The importance of silica in desert varnish. Geology, 34, 537-540.

Potter, R. M., and Rossman, G. R. (1979) The manganese- and iron-oxide mineralogy of desert varnish. Chemical Geology, 25, 79-94.

Roden, E. E., and Zachara, J. M. (1996) Microbial Reduction of Crystalline Iron (III) Oxides : Influence of Oxide Surface Area and Potential for Cell Growth Microbial Reduction of Crystalline Iron ( III ) Oxides : Influence of Oxide Surface Area and Potential for Cell Growth, 30(Iii), 1618-1628.

Rothery, D. A., Gilmour, I., and Sephton, M. A. (2011) In: An introduction to astrobiology (Second Edition), edited by Cambridge University Press, Cambridge, pp 1-360.

Rull, F., Sansano, A., Díaz, E., Canora, C. P., Moral, A. G., Tato, C., Colombo, M., Belenguer, T., Fernández, M., Manfredi, J.A.R. (2011) ExoMars Raman laser spectrometer for ExoMars. In SPIE Optical Engineering+ Applications (p. 81520J-81520J-13). International Society for Optics and Photonics. 
Sadooni, F. N., Howari, F., Edwards, H. G. M., and El-Saiy, A. (2010) Lithology, mineral assemblages and microbial fingerprints of the evaporite-carbonate sediments of the coastal sabkha of Abu Dhabi and their extraterrestrial implications. International Journal of Astrobiology, 9(03), 147-156.

Saiz-Jimenez, C. (1994) Production of alkylbenzenes and alkylnaphthalenes upon pyrolysis of unsaturated fatty acids. Naturwissenschaften, 81(10), 451-453.

Schelble, R. T., McDonald, G. D., Hall, J. A., and Nealson, K. H. (2005) Community Structure Comparison Using FAME Analysis of Desert Varnish and Soil, Mojave Desert, California. Geomicrobiology Journal, 22(7-8), 353-360.

Schulte, W., Viscor, T., Manhart, M., Hofmann, P., Baglioni, P., and Gmbh, K. (2010). Design and Testing of the ExoMars Sample Preparation and Distribution System. I-SAIRAS, 7-14.

Schulze-Makuch, D., and Irwin, L. N. (2008) In: Life in the Universe, edited by D. SchulzeMakuch and L.N. Irwin, Springer, Berlin.

Seiter, K., Hensen, C., Schröter, J., and Zabel, M. (2004) Organic carbon content in surface sediments_-defining regional provinces. Deep Sea Research Part I: Oceanographic Research Papers, 51(12), 2001-2026.

Stalport, F., Glavin, D. P., Eigenbrode, J. L., Bish, D., Blake, D., Coll, P., Szopa, C., Buch, A., McAdam, A., Dworkin, J.P., Mahaffy, P. R. (2012) The influence of mineralogy on recovering organic acids from Mars analogue materials using the one-pot derivatization experiment on the Sample Analysis at Mars (SAM) instrument suite. Planetary and Space Science, 67(1), 1-13. 
Vancampenhout, K., Wouters, K., Caus, A., Buurman, P., Swennen, R., and Deckers, J. (2008) Fingerprinting of soil organic matter as a proxy for assessing climate and vegetation changes in last interglacial palaeosols (Veldwezelt, Belgium). Quaternary Research, 69(1), 145-162.

Vandenabeelee, P., Edwards, H. G. M., and Jehlička, J. (2014) The role of mobile instrumentation in novel applications of Raman spectroscopy: archaeometry, geosciences, and forensics. Chemical Society Reviews, 43(8), 2628.

Vitek, P., Jehli ka, J., Edwards, H. G. M., Hutchinson, I., Ascaso, C., and Wierzchos, J. (2014). Miniaturized Raman instrumentation detects carotenoids in Mars-analogue rocks from the Mojave and Atacama deserts. Philosophical Transactions of the Royal Society A: Mathematical, Physical and Engineering Sciences, 372(2030), 20140196-20140196.

Vitek, P., Jehlička, J., Edwards, H. G. M., Hutchinson, I., Ascaso, C., and Wierzchos, J. (2014) Miniaturized Raman instrumentation detects carotenoids in Mars-analogue rocks from the Mojave and Atacama deserts. Philosophical Transactions of the Royal Society A: Mathematical, Physical and Engineering Sciences, 372(2030), 20140196-20140196.

Withnall, R., Chowdhry, B. Z., Silver, J., Edwards, H. G. M., and De Oliveira, L. F. C. (2003) Raman spectra of carotenoids in natural products. Spectrochimica Acta - Part A: Molecular and Biomolecular Spectroscopy, 59(10), 2207-2212.

Yoshioka, T., Handa, T., Grause, G., Lei, Z., Inomata, H., and Mizoguchi, T. (2005) Effects of metal oxides on the pyrolysis of poly(ethylene terephthalate). Journal of Analytical and Applied Pyrolysis, 73(1), 139-144. 
Final version available at: http://online.liebertpub.com/doi/abs/10.1089/ast.2016.1512

\section{Tables}

\begin{tabular}{|c|c|c|c|c|c|c|c|c|c|c|c|}
\hline Mineral & Formula & 2000 s & $1000 \mathrm{~s}$ & $800 s$ & $700 s$ & $600 \mathrm{~s}$ & 500 s & $400 \mathrm{~s}$ & $300 s$ & $200 s$ & $100 \mathrm{~s}$ \\
\hline Quartz & $\mathrm{SiO}_{2}$ & & 1162 & & & & & $\underline{465}$ & $\begin{array}{l}398, \\
355\end{array}$ & $264, \mathbf{2 0 7}$ & \\
\hline Plagioclase & $\begin{array}{ll}\mathrm{NaAlSi}_{3} \mathrm{O}_{8} & - \\
\mathrm{CaAl}_{2} \mathrm{Si}_{2} \mathrm{O}_{8} & -\end{array}$ & & & & & & $\frac{508-}{512}$ & $474-481$ & & 285 & \\
\hline Microcline & $\mathrm{KAlSi}_{3} \mathrm{O}_{8}$ & & & 813 & 749 & & $\underline{513}$ & $\begin{array}{l}476, \\
454,408\end{array}$ & & 266 & \\
\hline Muscovite & $\mathrm{KAl}_{2}\left(\mathrm{AlSi}_{3} \mathrm{O}_{10}\right)(\mathrm{OH})_{2}$ & & 1105 & & 705 & 651 & & 426 & & 266 & \\
\hline Haematite & $\mathrm{Fe}_{2} \mathrm{O}_{3}$ & & $\underline{1317}$ & & & $\frac{611}{615}$ & & $499, \underline{408}$ & & $\underline{291,224}$ & \\
\hline Magnetite? & $\mathrm{Fe}_{3} \mathrm{O}_{4}$ & & & & & 660 & & & & & \\
\hline Goethite & $\mathrm{FeO}(\mathrm{OH})$ & & & & & & $\underline{547}$ & & $\underline{396}$ & $\frac{297}{240,}, 207$ & \\
\hline Anatase & $\mathrm{TiO}_{2}$ & & & & & 636 & 516 & 445 & 398 & & 146 \\
\hline Rutile & $\mathrm{TiO}_{2}$ & & & & & 606 & & 418 & & 265 & \\
\hline Pseudobrookite & $\mathrm{Fe}_{2} \mathrm{TiO}_{5}$ & & & & 781 & 650 & & & 340 & 223,201 & \\
\hline Pyrolusite & $\mathrm{MnO}_{2}$ & & & & & $\overline{650}$ & 530 & & & & \\
\hline Jacobsite & $\mathrm{MnFe}_{2} \mathrm{O}_{4}$ & & & & & 620 & & & & & \\
\hline Carbon & $\mathrm{C}$ & & $\underline{1577}$ & & & & & & & & \\
\hline Beta-carotene & $\mathrm{C}_{40} \mathrm{H}_{56}$ & $\begin{array}{l}\text { 2647, } \\
2148\end{array}$ & $\begin{array}{l}\overline{\mathbf{1 5 1 2}} \\
\frac{\mathbf{1 1 5 5}}{1003}\end{array}$ & & & & & & & & \\
\hline
\end{tabular}


Final version available at: http://online.liebertpub.com/doi/abs/10.1089/ast.2016.1512

Table 2. Total organic carbon (TOC) and stable isotopic carbon composition expressed as the depletion relative to PDB standard $\left(\delta^{13} \mathrm{C}\right)$ for the seven samples of desert varnish.

\begin{tabular}{ccc}
\hline & TOC (\%) & $\square^{\mathbf{1 3}} \mathbf{C}(\%)$ \\
\hline DV1 & 0.23 & -23.5 \\
DV2 & 0.41 & -24.5 \\
DV3 & 0.23 & -24.2 \\
\hline CV1 & 0.15 & -24.3 \\
CV2 & 0.18 & -14.2 \\
CV3 & 0.24 & -24.0 \\
CV4 & 0.10 & -23.4 \\
\hline
\end{tabular}


Final version available at: http://online.liebertpub.com/doi/abs/10.1089/ast.2016.1512

\begin{tabular}{|c|c|c|c|c|c|}
\hline & AlkA & AlkE & $\mathrm{Ar}$ & FAME & PAH \\
\hline DV1 & 1.9 & 4.0 & 11.5 & 68.7 & 0.0 \\
\hline DV2 & 11.0 & 29.5 & 35.9 & 16.6 & 2.2 \\
\hline DV3 & 5.8 & 14.7 & 13.5 & 57.5 & 1.4 \\
\hline CV1 & 12.1 & 53.8 & 11.8 & 4.8 & 0.0 \\
\hline $\mathrm{CV} 2$ & 4.0 & 10.9 & 14.3 & 53.8 & 4.5 \\
\hline CV3 & 3.9 & 39.9 & 14.2 & 15.1 & 0.0 \\
\hline CV4 & 0.2 & 2.3 & 2.6 & 93.4 & 0.1 \\
\hline
\end{tabular}




\section{Figures}

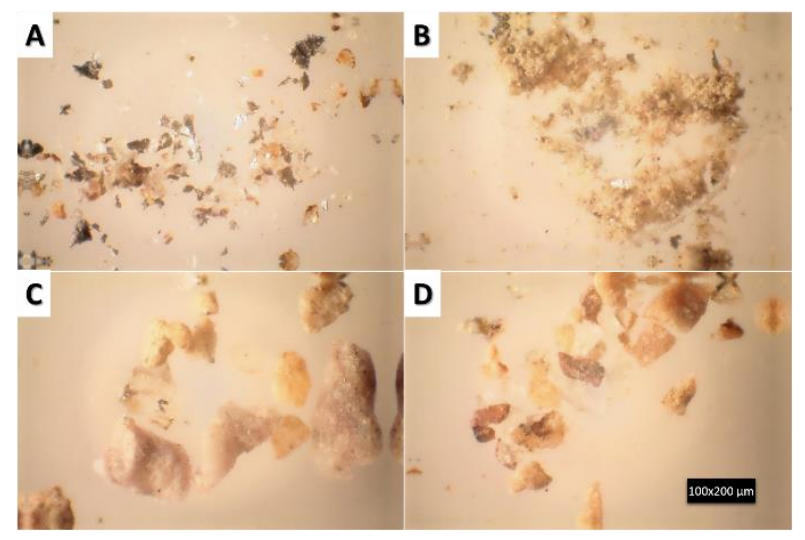

FIG.1. Representative images of the desert varnish grains torn off the sample (A) DV2, (B) DV3, (C) CV2 and (D) CV4.
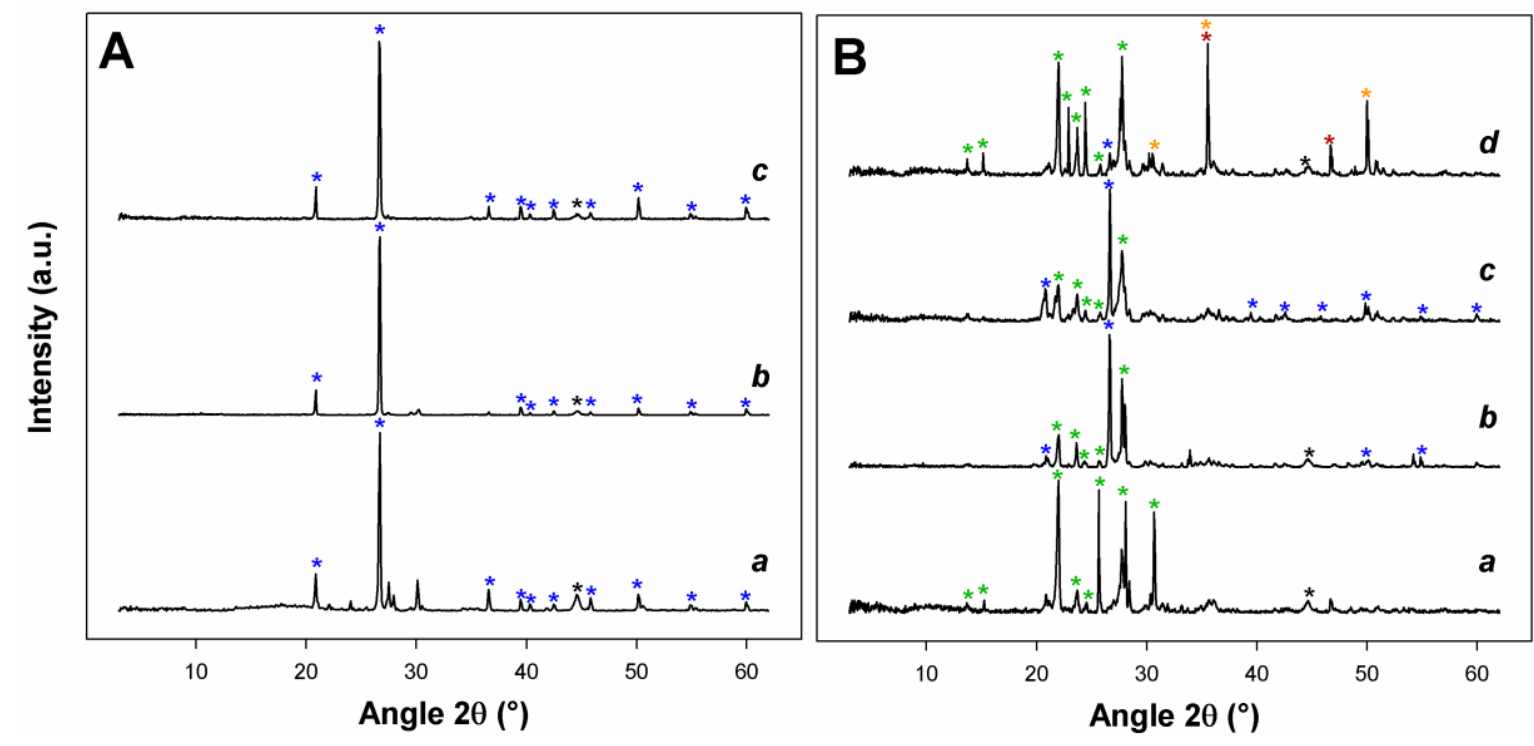

FIG.2. Powder X-ray diffractograms for the samples. Panel A: (a) sample DV1, (b) sample DV2 and (c) sample DV3. Panel B: (a) sample CV1, (b) sample CV2, (c) sample CV3 and (d) sample CV4. Peaks have been attributed to (*) quartz, (*) carbon, (*) hematite and (*) magnetite. (*) Plagioclase feldspar peaks are not attributed to one specific member of the solid solution due to significant patterns variation within the reference patterns. 

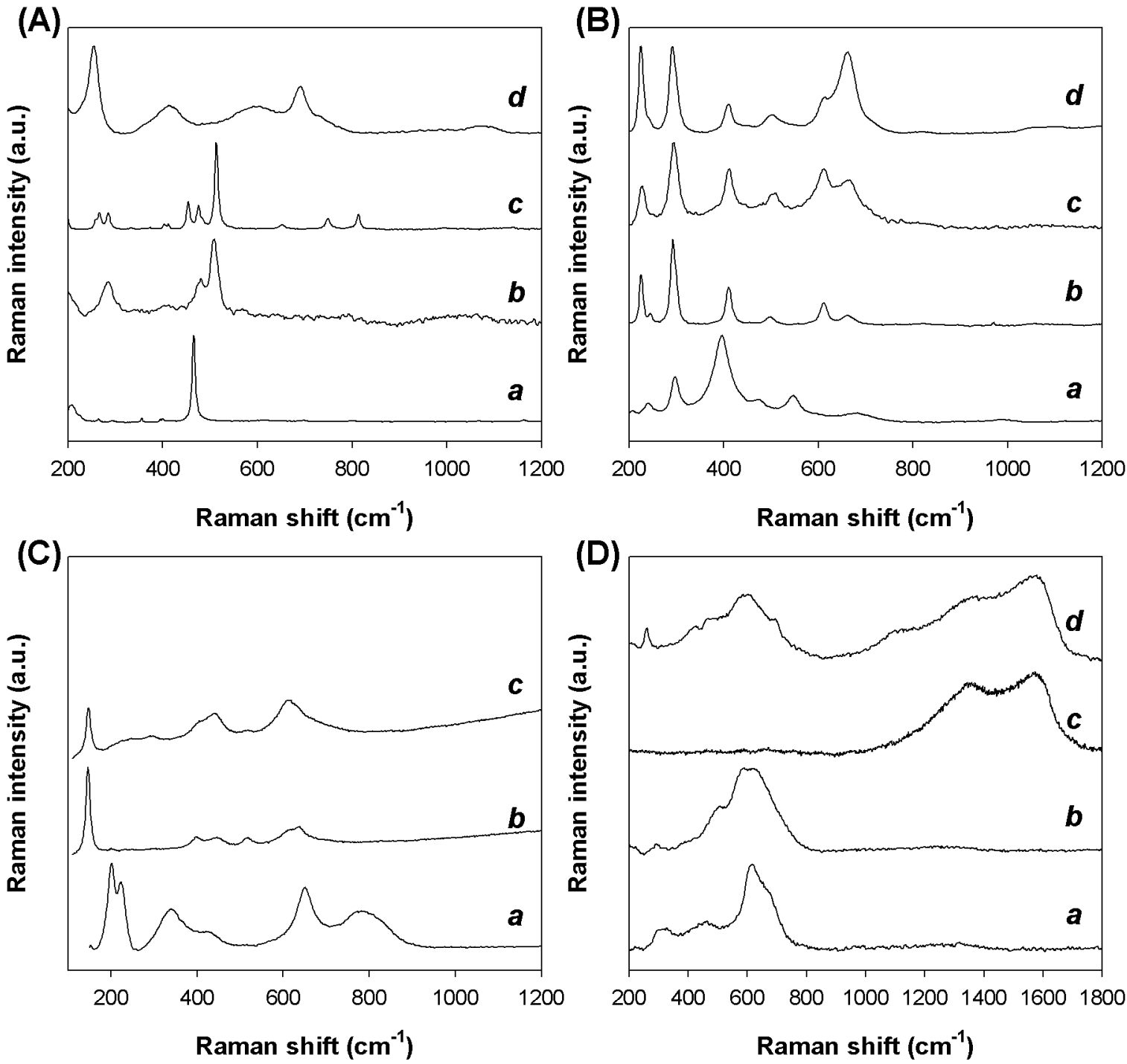

FIG.3. Selection of Raman spectra of different minerals observed for the desert varnish samples using a $633 \mathrm{~nm}$ excitation wavelength. (A) Raman spectra of several silicates: a-quartz, bplagioclase feldspar, c-microcline-feldspar and d-muscovite. (B) Raman spectra of iron minerals: a-goethite, b-hematite, c-hematite and magnetite, d-magnetite and hematite. (C) Raman spectra of titanium oxides: a-pseudobrookite, b-anatase and c-rutile. (D) Raman spectra of manganese oxides and disordered carbonaceous material: a-jacobsite, b-pyrolusite, cdisordered carbonaceous material and d-disordered carbonaceous material and pyrolusite. 


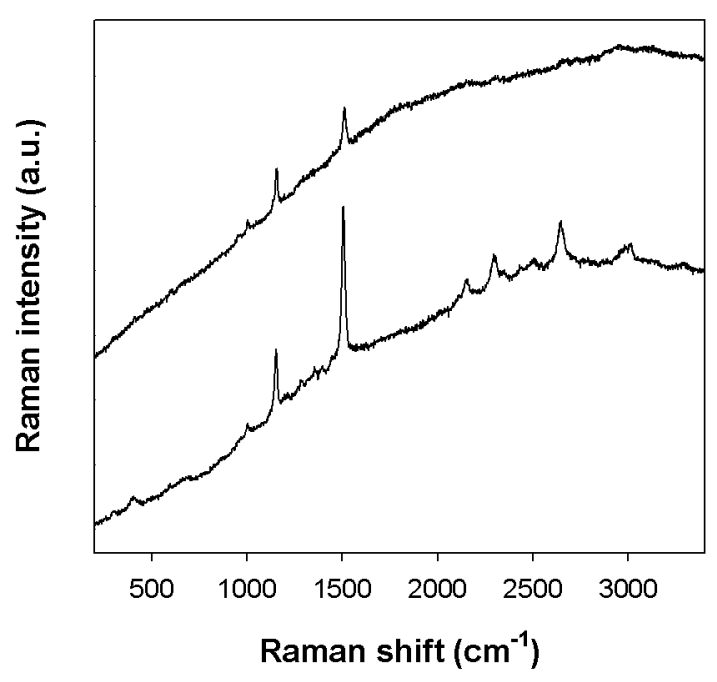

FIG.4. Raman spectra of carotenoid recoded on desert varnish using a $514 \mathrm{~nm}$ excitation wavelength.
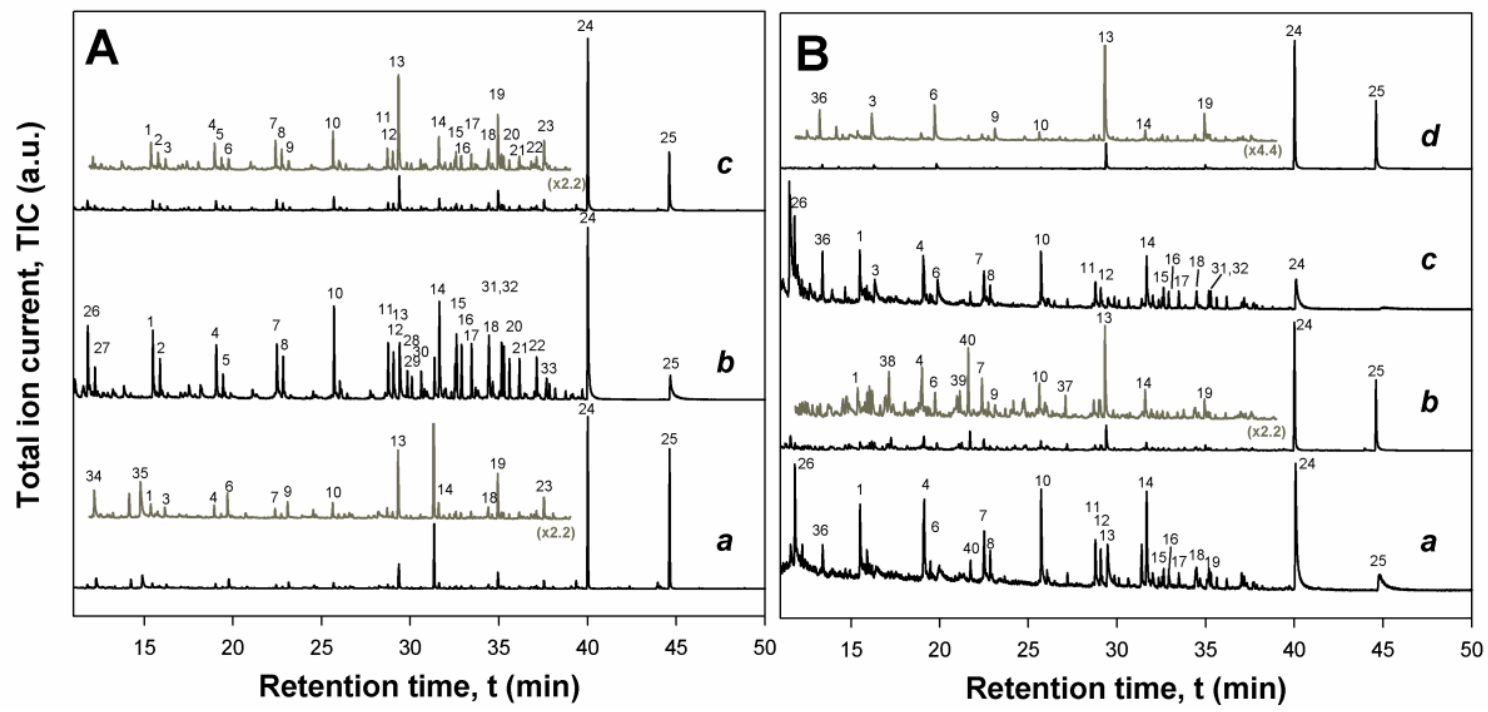

FIG.5. Chromatograms for the desert varnish samples. Panel A: (a) sample DV1, (b) sample DV2 and (c) sample DV3. Panel B: (a) sample CV1, (b) sample CV2, (c) sample CV3 and (d) sample CV4. The numbers refers to the organic compounds identified: (1) undecene, (2) undecane, (3) methyl ester of octanoic acid, (4) dodecene, (5) dodecane, (6) methyl ester of nananoic acid, (7) tridecene, (8) tridecane, (9) methyl ester of decanoic acid, (10) tetradecene, 
(11) pentadecene, (12) pentadecane, (13) methyl ester of dodecanoic acid, (14) methyl ester of hexadecanoic acid, (15) 1-butylheptylbenzene, (16) 1-propyloctylbenzene, (17) 1ethylnonylbenzene, (18) 1-methyldecylbenzene, (19) methyl ester of tetradecanoic acid, (20) 1propylnonylbenzene, (21) 1-ethyldecylbenzene, (22) 1-methylundecylbenzene, (23) methyl ester of pentadecanoic acid, (24) methyl ester of hexadecanoic acid, (25) methyl ester of octadecanoic acid, (26) decene, (27) decane, (28) 1-butylhexylbenzene, (29) 1propylheptylbenzene, (30) 1-ethyloctylbenzene, (31) 1-pentylheptylbenzene, (32) 1butyloctylbenzene, (33) 1-pentyloctylbenzene, (34) p-methylanisole, (35) methyl ester of benzoic acid, (36) methyl ester of 2-ethylhexanoic acid, (37) hexamethylbenzene, (38) tetramethylbenzene, (39) 4,7-dimethylindene, (40) pentaethylbenzene.

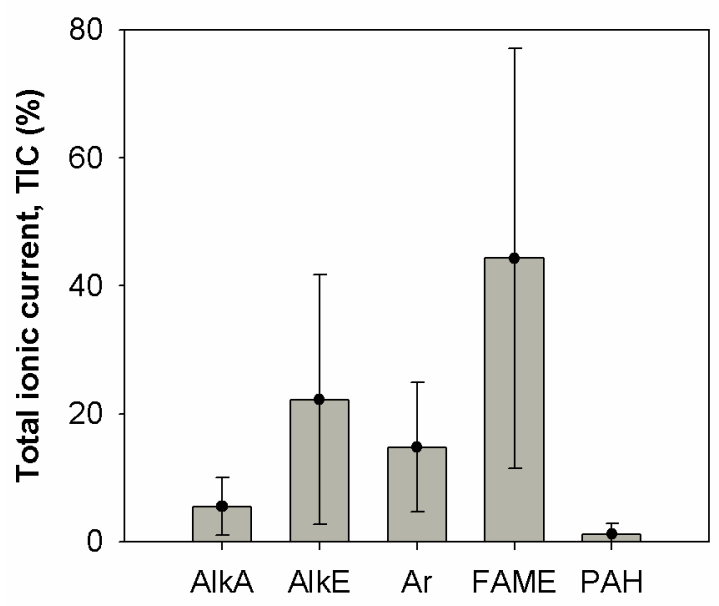

FIG.6. Relative amount of compounds classified in 5 groups according to their structure and chemical functions: alkane (AlkA), alkene (AlkE), fatty acid methyl ester (FAME), aryl (Ar) and polycyclic aromatic hydrocarbon (PAH). 